\title{
Medical History and the Wellcome Trust Centre
}

As many readers will already know, the Wellcome Trust has announced the closure of its Centre for the History of Medicine at University College London, with a two-year wind-down to commence in September 2010. Vivian Nutton and Roger Cooter took over as Acting Editors in October 2009, with Bill MacLehose and Stephen Jacyna as Reviews Editors. Among our immediate tasks was preparing for the retirement of the Assistant Editor, Caroline Tonson-Rye, later this year. We have also sought various publishing changes that would help keep costs down and the journal running. Negotiations on these fronts are ongoing.

The demise of the Centre and the possible departure of the whole editorial team raises problems that we are doing our best to resolve quickly and effectively. Although as yet nothing can be taken for certain, it seems extremely likely that Medical History will continue to be published in its present form and with its present publishing and editorial arrangements at least until the end of 2012. We have material in the pipeline that will take us well into 2011, if not 2012, and the small profit generated by the journal will allow us to continue unaided for a short while thereafter. We therefore continue to welcome submissions, and shall do our best to ensure that articles already accepted will indeed be published.

We hope to have a clearer picture in the near future. Meanwhile, our readers can be assured that the Editors will continue to strive to secure the survival of the journal. The result administratively may be a little different from what it is today, but we are confident that the stature and quality of Medical History can be maintained well into the future. 